\title{
Professional Stress in Journalism: A Study on Electronic Media Journalists of Bangladesh
}

\author{
Kazi Nazmul Huda1, Abul Kalam Azad² \\ ${ }^{1}$ Department of Business Administration, Southern University Bangladesh, Chittagong, Bangladesh \\ ${ }^{2}$ Department of Communication \& Journalism, University of Chittagong, Chittagong, Bangladesh \\ Email:knhuda@yahoo.com, azad2008_media@yahoo.com
}

Received 20 October 2015; accepted 2 December 2015; published 7 December 2015

Copyright (C) 2015 by authors and Scientific Research Publishing Inc.

This work is licensed under the Creative Commons Attribution International License (CC BY). http://creativecommons.org/licenses/by/4.0/

(c) (†) Open Access

\section{Abstract}

To meet the objectives of professional assignments, journalists often suffer from high level professional stress. The key objective of this study is to identify the major determinants of professional stress of journalists in electronic media. The study is, to a large extent, based on quantitative data collected through personal interview of 55 journalists of different private television channels of Bangladesh. The study reveals that inadequate support from management is the most heated cause of professional stress. However, the result also concludes "harassment" at workplace as an insignificant determinant. Other major determinants of stress are "unclear objective", "insecure job climate", "excessive time pressure", "friction", "long working hours" and "life threat" found in the study. However, though the study is very new to Bangladesh perspective, it is expected that it may help to develop professional stress management policies in this sector.

\section{Keywords}

Professional Stress, Stress Management, Causes of Stress, Electronic Media Journalists

\section{Introduction}

Job is an important part for many people's life and professional stress related to job is inevitable. There is a firm relation between profession-related stress and performance and there is evidence to support that the stress affects organizational and individual productivity (Bradley \& Sutherland, 1994). It is a contemporary issue both for the employees and employers and has become an unavoidable factor in the high performance corporate culture. There are many kinds of stresses in human life; but professional stress or the one that is related to job is unique 
in nature and may become "the silent killer" if not managed properly (Tarkovsky, 2007). Professional stress causes different kinds of physiological, psychological, and behavioral symptoms (Table 1) that may lead to collapse of human machine. Organizations and employees must deal with the issues of professional stress and should be smart in tackling stress to stay productive. Employees should be knowledgeable regarding the causes to meet professional stress on time. Professional stress occurs when the employees find disparity between job and work environment especially when they need to work under different categories of pressures and anxieties (Nawe, 1995; Maslach, 2003). Continuing a stressful job may lead to sudden burnout situation at workplace, and could develop negative self-image and other symptoms of stress (Caputo, 1991).

The press serves the role of delivering new information quickly, accurately, and consistently (Sang-young \& Cho, 2014) and the electronic media in Bangladesh has grown rapidly and currently, playing a significant role in contributing to the entertainment industry. Since 1997, the industry witnessed a significant qualitative and quantitative change when this sector was privatized. After the independence of Bangladesh in 1971, there was only TV channel in the country namely Bangladesh Television (BTV) run by the government with limited number of programs and news. However, since 1997 the industry has achieved significant expansion with 41 private television channels. News is a common product of all TV channels and due to more competition caused by the increasing number of television channels (Azad \& Hussain, 2015), enormous stress on the news reporters is given.

Journalism is one of the most stressful careers that have to deal with deadlines, busy work environments, tight schedules, extensive travelling, fulfilling the demands of the editors, and the fear of being killed and laid off (Shmoop, 2014). The profession is been rated in the top ten stressful jobs amongst all the professions in the world and faces a shrinking job market (Shapley, 2013). A large number of news reporters in Bangladesh had complained that they could not even report fair news by the threats and pressure of employers and effected parties (Azad \& Hussain, 2014). Journalists are often subject to dangerous and life threatening situations and encounter considerable amount of psychological pressure besides other stress, i.e. work overload and job insecurity. Existing studies hardly succeeded in finding out finding out the stress depicts, and rarely generated many ideas to mitigate professional stress (Teasdale, 2006). Our study intends to close the gap.

When professional stress takes a massive shape, it affects the performance of the organization, turns down the quality of individual productivity, deteriorates physical condition, weakens social relations, and ruins family life. Stress at work is inevitable in today's high performing and competitive corporate culture. However, active interventions may minimize the level of stress to bring a balance between work and life (Baker, 1985). It is the responsibility of the employers and employees to identify the causes of professional stress and should measure its impact on performance to maintain a healthy and productive work life and to avoid the negative consequences. The study tires to address the specific causes of stress of electronic media journalists of Bangladeshi private television channels and endeavors to reveal their opinions about the determinants of professional stress.

\section{Objectives of the Study}

1) To identify and rank the determinants of professional stress of electronic media journalists.

2) To recommend specific interventions to minimize professional stress of them.

Table 1. Types of symptoms of professional stress.

\begin{tabular}{cccc}
\hline Sl. No. & Physiological & Mental/ Psychological & Behavioral \\
\hline 1 & Headaches & Anxiety & Irritable/aggressive \\
2 & Migraines & Tension & Withdrawn \\
3 & Changing sleep patterns & Irritability & Social isolation \\
$\mathbf{4}$ & Stomach disorders & Low self-esteem & Consumption of alcohol, tobacco, tea/coffee, drugs, self-medication \\
$\mathbf{5}$ & Raised blood pressure & Forgetfulness & Non co-operative \\
$\mathbf{6}$ & Muscle spasms & Feeling powerless & Accident-prone \\
$\mathbf{7}$ & Back/shoulder/neck pain & & Less sociable \\
$\mathbf{8}$ & Sense of feeling unwell & & Negligence in personal appearance \\
$\mathbf{9}$ & Unwillingness to work & & \\
\hline
\end{tabular}

Source: Newstrom and Davis (2007) and Authors. 


\section{Literature Review}

Professional stress could be a chronic life-threatening syndrome raised from the work conditions that may negatively influence employees' productivity and personal well-being. According to World Health Organization (1948) stress are states of comprehensive physical, mental, and social illness in a person. Though, no profession is stress-free; and has some degree of strain, and anxiety that could result in productivity and satisfaction at work or may lead to negative results like mental and physical illness if the stress is excessive (Teasdale, 2006). Work-related stress is considered as the foremost cause of a wide range health problems (Kivimaki et al., 2006), and is strongly connected to staff turnover, absenteeism, poor morality and declining productivity (Noblet \& Lamontagne, 2006). Increasing level of workplace stress can lead to serious legal allegation against any employers like compensation claims, disciplinary issues, and workplace violence Brady (cited in Babcock, 2009). According to Canadian Underwriter (2004), factors that causes professional stress include conflict/friction among the co-worker (University of Cambridge, 2014; Friedman et al., 2000), bulling by the supervisors, job insecurity, and the absence of freedom in decision-making (University of Cambridge, 2014), and some personal issues i.e. family pressure, financial constrains abuse etc. It could be also generated out of fear of uncertainty, unrealistic deadlines and interpersonal conflict (Babcock, 2009). Professional stress mostly occurs by long working hours that may cause cardiovascular attack (Uehata, 1991). It also interferes family life and psychological distress (Major et al., 2002). In many times, bullying and organizational incivility are one of the most upsetting issues for the employees (Gholipour et al., 2011), that might be caused by allegation, rudeness, frightening, malevolence, insult which directs to aggravation, threat, disrespect, and deterioration of self-confidence (Lee, 2000). However, the more common psychological job stress is anxiety, and depression that negatively impacts work environment (Teasdale, 2006). As stated in the U.S Department of Health, Professional stress is harmful physical and emotional responses when the job description of a job does not match the capabilities, resources, or needs of the employees. The fight to stabilize the work and family life is purely one of the many stressors that an employee faces at work (Tyler, 2006). In many times professional stress are created by pressure of ethical conduct (Ulrich et al., 2007; Glicken, 2013). To combat the stress the managers must audit and acknowledge the presence of stress at workplace should undertake stress management interventions to reduce the levels of stress of their employees (Sidle, 2008). According to Jones et al. (2003), it is found that stress management interventions improve physical and mental health, reduces costs of the employers, and facilitates the reintegration of effected employees into workplace and it is an integral component of health promotion program of an organization (Kobayashi, 1997). There are three broad categories of stress management interventions exposed by Ivanevich et al. (1990), i.e. reducing the current stressors, identifying the employees under stress and aiding the employees to adjust with the situation that causing stress. DeFrank and Cooper, (1987) recommended, stress management as individual interventions like relaxation and autonomy at work. Stress management techniques could be divided into two types: environmental management (Murphy, 1999) which is an endeavor to organize work environments to reduce the cause of stress; and the approach that aids the employees to deal efficiently with various types of stressful condition (Hardy \& Barkham, 1999). Physical and mental health is a potential source of work related injury or disease and both the employer and employee have the lawful right, responsibility and accountability to help each other to identify, acknowledge and mitigate stress and stressors to ensure sustainable productivity and workplace harmony.

\section{Methodology, Scope and Limitation of the Study}

The methodology of this study was designed to address of objectives of the research. The study is descriptive in nature, followed inductive research approach and a survey based research strategy. The methodological choice of the research is both qualitative and quantitative. The survey intervenes to collect required information and data through structured questionnaire. An extensive literature review was conducted to identify the most common determinants of professional stress (Table 2) and the questionnaire was developed based on the identified variables. Total 55 journalists of fourteen private TV channels were interviewed with a view to making the study informative and representative and a close-end questionnaire survey was conducted too. The questionnaire contains 15 questions and a 5-point likert rating scale (5 Strongly agree...1 Strongly disagree) were used to capture the opinion of the respondents about important determinants of professional stress. The respondents were mostly male news reporters and camerapersons who have permanently employed in this sector for last five years. The survey was carried out during May to June 2015. 
Table 2. Important determinants of professional stress.

\begin{tabular}{rlll}
\hline & Determinant of Professional Stress & \multicolumn{1}{c}{ Code } & \\
\hline 1 & Unclear objective & Objective & Semmer (2007) \\
2 & Excessive time pressure & Time pressure & Semmer (2007) \\
3 & Unachievable deadline & Deadline & Turnage \& Spielberger (1991); University of Cambridge (2014) \\
4 & Long work hour & Work hour & Sethi et al. (2004); Uehata (1991); University of Cambridge (2014) \\
5 & Work overload & Overload & Sethi et al. (2004); Semmer (2007); University of Cambridge (2014) \\
6 & Fast work & Fast & Sethi et al. (2004); Major et al. (2002) \\
7 & Less freedom & Freedom & University of Cambridge (2014); Canadian underwriter (2004) \\
8 & Inadequate support & Support & Semmer (2007) \\
9 & Workplace harassment & Harassment & Semmer (2007) \\
10 & Friction & Friction & University of Cambridge (2014); Friedman et al. (2000) \\
11 & Pressure for un-ethical conducts & Ethics & Ulrich et al. (2007); Glicken (2013) \\
12 & Insufficient compensation package & Compensation & Canadian underwriter (2004) \\
13 & Family pressure & Family & Major et al. (2002); Canadian underwriter (2004) \\
14 & Possibility of life threat & life threat & Zakaria \& Azad (2009) \\
15 & Insecure job climate & Job security & Semmer (2007); University of Cambridge (2014) \\
\hline
\end{tabular}

Source: Literature Review.

Data analysis of the study used intensive statistical tool such as multivariate analysis technique, specifically Exploratory Factor Analysis (EFA) with the support of SPSS. Important determinants of professional stress have been identified by considering the loading value of each variable (Table 2). Higher loading value is considered as high importance of professional stress and vice versa. The respondents were asked about their feelings of stress in terms of the variables, i.e. are they clear about their job objectives? Do they feel time pressure? Are they overloaded with responsibilities? Is there a friction among the peers? What about their feelings of job security. Are they under life threat?, and so on. The researchers have their level best to cover up many issues regarding the professional stress of journalists. However, the study has some limitations too. Major limitation of the study is the scope of the research, as the area does not cover all the television channels of Bangladesh due to financial constrain of the researcher. The sample size was limited to 55 as the research was supposed to be completed in a limited period. The demographic data of the respondents, i.e. age, gender, and others are not considered in the study. The researcher was bias to theories of stress management only to develop the model of the research and interpretation \& analysis of the data were organized in accordance to that. The possibility of respondent's responses being biased cannot be ruled out too.

\section{Findings}

The key objective of the study was to identify the important determinants of professional stress among electronic media journalists of Bangladeshi private television channels. In order to fulfill the research objective, and at the very outset, factor analysis was conducted, as it is an effective statistical tool used to describe variability among observed, correlated variables in terms of a potentially lower number of unobserved variables. Principal Component Analysis was conducted on fifteen (15) variables (Table 3) where the KMO value of study was found to be 0.477 and the TVE value is $67.25 \%$ at the first stage of EFA. The result shows that, these variables in combined can explain more than $67 \%$ of the total variation of professional stress. However, the variable namely "workplace harassment" was found to be cross-loaded (loading in two dimensions) and that might have caused the lower KMO value. That is why the variable "harassment" is dropped from the study. Workplace harassment may not be an important determinant among the reporters and camerapersons as most of the time they work outdoor and have less formal interaction and indoor responsibilities. However, crime and corruption reporters face somewhat harassment outdoor by the parties affected by their news reports.

After dropping harassment from the study, KMO value has increased from 0.47 to 0.512 and which is significant too. This means the problem initially was might be due to less important variable, harassment. Principal 
Table 3. Factor summary.

\begin{tabular}{|c|c|c|c|c|}
\hline Factor & Variables & Loading Value & Eigenvalue & Percentage of Variation Explained \\
\hline \multirow{3}{*}{1} & Insecure job CLIMATE & 0.838 & \multirow{3}{*}{2.530} & \multirow{3}{*}{18.072} \\
\hline & Fast work & 0.692 & & \\
\hline & Less freedom & 0.601 & & \\
\hline \multirow{3}{*}{2} & Friction & 0.800 & \multirow{3}{*}{2.015} & \multirow{3}{*}{14.395} \\
\hline & Family pressure & 0.691 & & \\
\hline & Insufficient compensation package & 0.618 & & \\
\hline \multirow{2}{*}{3} & Excessive time pressure & 0.834 & \multirow{2}{*}{1.529} & \multirow{2}{*}{10.925} \\
\hline & Unachievable deadline & 0.615 & & \\
\hline \multirow{3}{*}{4} & Long working hours & 0.742 & \multirow{3}{*}{1.468} & \multirow{3}{*}{10.485} \\
\hline & Work overload & 0.661 & & \\
\hline & Pressure for un-ethical conducts & 0.606 & & \\
\hline \multirow{2}{*}{5} & Unclear objective & 0.849 & \multirow{2}{*}{1.102} & \multirow{2}{*}{7.847} \\
\hline & Possibility of life threat & 0.710 & & \\
\hline 6 & Inadequate support & 0.888 & 1.026 & 7.329 \\
\hline
\end{tabular}

Source: Compiled from SPSS Version 20.

Component Analysis have clustered remaining 14 variable under six broad factors and these factors covered around $69 \%$ of the total variance of the professional stress. Factor loading of the variables determining the degree of significance of each factor and the Eigenvalue and percentage of variation explained by the factor are shown in Table 3. The given result provides statistical evidence to support the newly identified six factors of professional stress factors as coded F1, F2, F3, F4, F5 and F6 (Table 3). This shows a firm influence of these variables to cause professional stress as these variables covered 69.081 variances (Appendix 1). Under factor 1 , insecure job climate, fast work and less freedom determinants are clustered with the eginenvalue of 2.530 and the percentage of variation explained 18.072 that show significant influence in causing professional stress. The factor may cause both mental and physical stress in professional life. Factor 2 contains three variables friction, Family Pressure, and insufficient compensation package with the eigenvalue 2.015 and the percentage of variation explained 14.395. This factor mostly creates mental and behavioral stress. Factor 3 contains the variables, such as excessive time pressure, and unachievable deadline. The eigenvalue of this dimension is found to be 1.529 and the percentage of variation explained at 10.925. This factor is mostly responsible in causing physical and mental stress in the profession. Factor 4 encloses three variables termed as long work hour, work overload, and Pressure for un-ethical conducts. The eginvalue of this factor is 1.468 and the percentage of variation explained 10.485. Presence of this factor at profession may cause physical, mental, and behavioral stress. Variables enfold in Factor 5 namely unclear objective and life threat with the eginvalue 1.102 and the percentage of variation explained 7.847. The factor might cause physical and mental stress in the profession. Factor 6 contains only one determinants inadequate support having the eginvalue 1.026 and the percentage of variation explained 7.329. This factor may lead to causing mental and behavioral stress in the profession. Though loading table shows that, 14 variables are grouped under six dimensions/factor (Table 4 and Table 5), but the plot diagram (Figure 1) argues that they are close variables and somewhat uni-dimensional as we see the circles and their close proximity in the diagram. This means maximum determinants of professional stress are uni-dimensional and interrelated to each other in causing stress.

\section{Discussion}

The study shows a clear picture of the presences of professional stress in electronic media journalism and identified the influencing determinants that causing stress in their professional life. The main findings of the study are:

1) The six factors that are found out of 14 variables.

2) Loading values of the variables are greater than 0.50 and found positive in relation to stress.

3) Some having highly significant relationship, as their loading value is more than 0.80 . Highest loading vale amongst 14 purified variables is "inadequate support" (loading is .888). It means the journalist needs support from many dimensions like from the management, peer group, subordinates to cover and broadcast news and a clear indication to the necessity of teamwork in this profession is quite obvious. The journalist may need external 
Table 4. Total variance explained.

\begin{tabular}{|c|c|c|c|c|c|c|}
\hline \multirow{2}{*}{ Component } & \multicolumn{3}{|c|}{ Initial Eigenvalues } & \multicolumn{3}{|c|}{ Rotation Sums of Squared Loadings } \\
\hline & Total & $\%$ of Variance & Cumulative \% & Total & $\%$ of Variance & Cumulative \% \\
\hline 1 & 2.530 & 18.072 & 18.072 & 1.875 & 13.394 & 13.394 \\
\hline 2 & 2.015 & 14.395 & 32.468 & 1.734 & 12.387 & 25.781 \\
\hline 3 & 1.529 & 10.925 & 43.393 & 1.708 & 12.196 & 37.977 \\
\hline 4 & 1.468 & 10.485 & 53.878 & 1.590 & 11.357 & 49.335 \\
\hline 5 & 1.102 & 7.874 & 61.752 & 1.463 & 10.451 & 59.785 \\
\hline 6 & 1.026 & 7.329 & 69.081 & 1.301 & 9.296 & 69.081 \\
\hline 7 & 0.925 & 6.607 & 75.687 & & & \\
\hline 8 & 0.829 & 5.925 & 81.612 & & & \\
\hline 9 & 0.677 & 4.834 & 86.446 & & & \\
\hline 10 & 0.550 & 3.928 & 90.374 & & & \\
\hline 11 & 0.408 & 2.913 & 93.287 & & & \\
\hline 12 & 0.382 & 2.728 & 96.015 & & & \\
\hline 13 & 0.304 & 2.175 & 98.190 & & & \\
\hline 14 & 0.253 & 1.810 & 100.000 & & & \\
\hline
\end{tabular}

Extraction Method: Principal Component Analysis.

Table 5. Rotated component matrix ${ }^{\mathrm{a}}$.

\begin{tabular}{|c|c|c|c|c|c|c|}
\hline & \multicolumn{6}{|c|}{ Component } \\
\hline & 1 & 2 & 3 & 4 & 5 & 6 \\
\hline Unclear objective & & & & & 0.849 & \\
\hline Excessive time pressure & & & 0.834 & & & \\
\hline Unachievable deadline & & & 0.615 & & & \\
\hline Long work hour & & & & 0.742 & & \\
\hline Work overload & & & & 0.661 & & \\
\hline Fast work & 0.692 & & & & & \\
\hline Less freedom & 0.601 & & & & & \\
\hline Inadequate Support & & & & & & 0.888 \\
\hline Friction & & 0.800 & & & & \\
\hline Pressure for un-ethical conducts & & & & 0.606 & & \\
\hline Insufficient compensation package & & 0.618 & & & & \\
\hline Family pressure & & 0.691 & & & & \\
\hline Possibility of life threat & & & & & 0.710 & \\
\hline Insecure job climate & 0.838 & & & & & \\
\hline
\end{tabular}

Extraction Method: Principal Component Analysis. Rotation Method: Varimax with Kaiser Normalization.

${ }^{\mathrm{a}}$ Rotation converged in 8 iterations.

supports from the governmental authorities and stakeholders of media like politicians, civil societies, and human right activists to perform their professional responsibility fairly and freely.

The second most important determinants of stress is "unclear job objectives" with the loading value of 0.849 . It means significant stress can be created if the job objective is not making clear to the journalists. Objective in journalism can be of two types, one is professional objective, and another is task related objective that is time bound. The first situation of unclear objective may occur if they feel or find a gap between the dignity of the profession and the reality of work life. Because in real life, it is very tough to broadcast true news with the possibility of life threat (0.710), less freedom to work (0.601), pressure for unethical conduct (0.606). Zakaria \& Azad (2009) 


\section{Component Plot in Rotated Space}

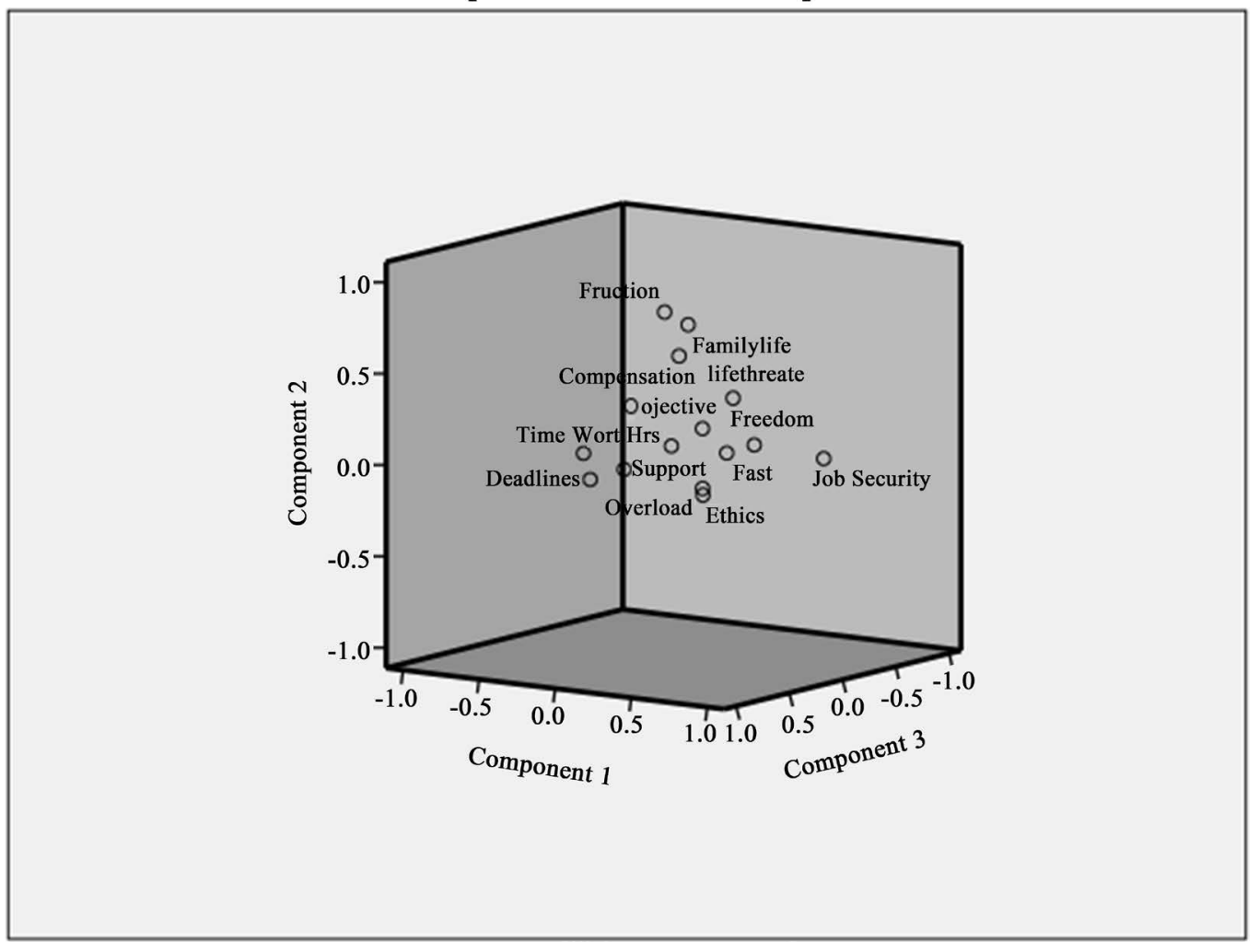

Figure 1. Plot diagram.

also found the same in their study and stated that, this profession is full of stress with life threat, unethical pressure by the owners as most of them are politically connected and therefore, put pressure on the journalist to perform true responsibility. The second situation of unclear objective may occur mostly for the presences of factor 2 where the fourth highest loading value excessive time pressure is present with 0.834 because the work objective means, task to be finished in a given time.

Third highest variable is "insecure job climate" with the loading value of 0.838 . The journalist could be feeling job insecurity as the privet job culture in Bangladesh is not yet matured with the concept of employee retention strategies. Zakaria \& Azad (2009) also found the same findings and stated that this profession is full of uncertainty, with no job security, and no human resource policy and rules. Friction is common in this profession where greater degree of interdependency is required to accomplish exclusive assignments. Every news is a unique project work and there is a presence of aggressive competition among the reporters for the priority of broadcasting may create a competitive environment that may lead to friction among the peers and superiors. So, we see a higher loading value of the variable "friction" $(0.800)$ in the study. Bangladesh frequently faced politically turmoil situations and the TV reporters had to run after breaking news and needed to work restless for long hours. That is why "long working hour" with the loading of 0.742 is another important determinant of professional stress to them. From the study, it is revealed that, stress in electronic media journalism is caused by multiple determinants and they are interrelated, too.

\section{Recommendations}

Professional stress is not determined by only job related stress. There is an existence of external stressors like, family pressure, life threat, and unethical environment. Therefore, a holistic approach could be taken by the top management of the TV channels to design effective interventions in identifying and reducing the important determinants of professional stress. Tailored-made stress management programs like stress reporting and auditing, job redesign, grievances management program, counseling, meditation and psychotherapy could be under take to bring stability in this noble profession and support the journalist to cope with the stressors. Sidle (2008) and 
Bradley \& Sutherland (1994) suggested the same in their study. Stabilizing functions should act to sustain the process continuity through periodic stress audit and feedback.

At the beginning, awareness program on professional stress could be organized to aid the management and the journalists to take control over work and life. Encourage peer support culture among the journalists through promoting team culture in this profession. Reporters could be empowered with greater flexibility in decision-making and due assistance to attain their objective without stress. Effective teamwork will allow the journalists to share responsibilities and value each other priority and develop a caring and supportive environment to accomplish stressful assignments. Bradley \& Sutherland (1994) also suggested conducting training on teambuilding and relaxation. Some specific stress management interventions like relaxation program to be arranged for the journalists. Most of the research on stress management discussed the success of relaxation program in combating stress. Relaxation program may include yearly outdoor family events could be organized to keep them charged and stress free. Employee wellbeing program, i.e. recreations facility, family events, family friendly work environment, recognition, and reward for their wellness. Teasdale (2006) also mentioned to bring a balance in professional life. Work life balance issue is to be considered as a key issue and employee concierge service could be introduced to help busy employees to make their family life easy. This employee assistance service may include household services, and onsite medical care, utility bill payment, repair services, banking services, legal advice services etc to reduce off-the-job concerns, increase on-the-job focus, and company loyalty, to balance work and personal lives and enjoy hassle free and peaceful life. Some of the government organizations Bangladesh, like military services, organizations under petroleum corporations, port authorities, are provided with these types of services.

Press Club, the association of the journalists in Bangladesh, may take some measures to help the journalist by taking programs like counseling, advocacy program, policy formulation to reduce stress and mainly a unified service rules for the journalists to promote better human resource management practices in this profession.

Government should undertake protection programs for the journalist by providing security by law enforcing agencies. The journalists killed in the line of duty should be provided with justice and their family members should be taken under governmental rehabilitation program.

\section{Conclusions}

Electronic media journalists are playing a pivotal role in promoting democracy, human rights, good governance, and other social issues. So, their stress in the professional life should be assessed with due diligence. This study finds the presence of professional stress among the Bangladeshi electronic media journalists with a significant value. However, the professional stress of TV journalists are largely dependent on less support, unclear objective, insecure job climate, time pressure, friction, long-hour work and a new discovery that is life threat. Harassment does not come as an important determinant in this profession but external bodies usually harass them. Adequate support, job security, positive interpersonal relationship among the co-employees, better salary, and fringe benefits could bring higher efficiency in this profession. However, the journalists should take some personal initiatives to be knowledgeable about the ways of handling professional stress and develop a self-help approach to reduce the degree of stress to remain productivity as well. Journalism has become a critical occupation day by day. In search for news stories, they need to see, write, and witness many unpleasant incidents that could be stressful and may end with life threatening consequence of their life. A well thought-through, proactive approach of professional stress management could be organized by all the stakeholders of journalism to combat stress and to make this challenging profession pressure-free, productive, and enjoyable.

Professional stress is a multi-dimensional situation of a person's life that could be caused by off and on the job stressors. In managing people with productivity and job satisfaction, professional stress management is a prime issue of consensus and consciousness for the new generation managers, employees, and the policy makers at large. The concept of professional stress and its major determinants could be an important issue of study to bring efficiency in work and balance in social life. The research could be helpful to identify the symptoms of stress, outcome, and impact of stress on performance of the journalists in the future.

\section{References}

Azad, A. K., \& Hussain, S. (2015). IBS Journal, Vol. 22. Bangladesh: Institute of Bangladesh Studies.

Baker, D. B. (1985). The Study of Stress at Work. Annual Review of Public Health, 6, 367-381.

http://dx.doi.org/10.1146/annurev.pu.06.050185.002055 
Bradley, J., \& Sutherland, V. (1994). Stress Management in the Workplace Taking Employees’ Views into Account. Employee Counseling Today, 6, 4-9. http://dx.doi.org/10.1108/13665629410060443

Brady, J. (Cited from Babcock, P.) (2009). Workplace Stress? Deal with It. HR Magazine, May 2009, 67.

Canadian Underwriter (2004). Stress from Workplace Conflict. www.canadianunderwriter.ca

Caputo, J. (1991). Stress and Burnout in Library Service. Phoenix, AZ: Oryx Press.

DeFrank, R., \& Cooper, C. (1987). Worksite Stress Management Interventions: Their Effectiveness and Conceptualization. Journal of Managerial Psychology, 2, 4-10. http://dx.doi.org/10.1108/eb043385

Friedman, R. A., Tidd, S. T., Currall, S. C., \& Tsai, J. C. (2000). What Goes around Comes around: The Impact of Personal Conflict Style on Work Conflict and Stress. International Journal of Conflict Management, 11, 32-55. http://dx.doi.org/10.1108/eb022834

Gholipour, A., Sanjari, S., Bod, M., \& Kozekanan, S. (2011). Organizational Bullying and Women Stress in Workplace. International Journal of Business and Management, 6, 234. http://dx.doi.org/10.5539/ijbm.v6n6p234

Glicken, M. D. (2013). Treating Worker Dissatisfaction in a Time of Economic Change. Elsevier

Hardy, G., \& Barkham, M. (1999). Psychotherapeutic Interventions for Work Stress. In J. Firth-Cozens, \& R. L. Payne (Eds.), Stress in Health Professionals: Psychological and Organizational Causes and Interventions (pp. 247-259). Chichester: John Wiley \& Sons.

Ivanevich, J., Matteson, M., Freedman, S., \& Philips, J. (1990). Worksite Stress Management Interventions. American Psychologist, 45, 252-261. http://dx.doi.org/10.1037/0003-066X.45.2.252

Kivimaki, M., Virtanen, M., \& Elovainio, M. (2006). Work Stress in the Etiology of Coronary Heart Disease-A MetaAnalysis. Scandinavian Journal of Work, Environment \& Health, 32, 431-442. http://dx.doi.org/10.5271/sjweh.1049

Kobayashi (1997). Japanese Perspective of Future Work Life. Scandinavian Journal of Work, Environment \& Health, 23, 66-72.

Lee, D. (2000). An Analysis of Workplace Bullying in the UK. Personnel Review, 20, 593-610. http://dx.doi.org/10.1108/00483480010296410

Major, V. S., Klein, K. J., \& Ehrhart, M. G. (2002). Work Time, Work Interference with Family, and Psychological Distress. Journal of Applied Psychology, 87, 427-436. http://dx.doi.org/10.1037/0021-9010.87.3.427

Maslach, C. (2003). Job Burnout: New Directions in Research and Intervention. Current Directions in Psychological Science, 12, 189-192. http://dx.doi.org/10.1111/1467-8721.01258

Murphy, L. (1999). Organizational Interventions to Reduce Stress in Health Care Professionals. In J. Firth-Cozens, \& R. L. Payne (Eds.), Stress in Health Professionals: Psychological and Organizational Causes and Interventions (pp. 149-162). Chichester: John Wiley \& Sons.

Nawe, J. (1995). Work-Related Stress among the Library and Information Workforce. Library Review, 44, 30-37. http://dx.doi.org/10.1108/00242539510093674

Newstrom, J., \& Davis, K. (2007). Organizational Behavior: Human Behavior at Work. New Delhi: McGraw-Hill.

Noblet, A., \& Lamontagne, A. D. (2006). The Role of Workplace Health Promotion in Addressing Job Stress. Health Promotion International, 21, 346-353. http://dx.doi.org/10.1093/heapro/dal029

Sang-young, P., \& Cho, S. (2014). Effects of Journalists’ Job Stress Factors on Physical Conditions. Advanced Science and Technology Letters, 72, 11-15

Semmer, N. K. (2007). Recognition and Respect (or Lack Thereof) as Predictors of Occupational Health and Well-Being. Paper Presentation at World Health Organization, Geneva: WHO.

Sethi, V., King, R. C., \& Quick, J. C. (2004). What Causes Stress in Information System Professionals? Communications of the ACM, 47, 99-102. http://dx.doi.org/10.1145/971617.971623

Shapley, L. (2013). Most Stressful Jobs: Journalism Careers Make 2013 List. The Denver Post, 16 April 2013. http://blogs.denverpost.com/editors/2013/04/16/media-jobs-make-list-of-top-stressful-careers-of-2013/857/

Sidle, S. (2008). Workplace Stress Management Interventions: What Works Best? Academy of Management Perspectives, 22, 111-112. http://dx.doi.org/10.5465/AMP.2008.34587999

Tarkovsky, S. (2007). Professional Stress—All You Need to Know to Beat It. http://EzineArticles.com/434206

Teasdale, E. L. (2006). Workplace Stress. Psychiatry, 5, 251-254. http://dx.doi.org/10.1053/j.mppsy.2006.04.006

Turnage, J. J., \& Spielberger, C. D. (1991). Job Stress in Managers, Professionals, and Clerical Workers. Work \& Stress, 5, 165-176. http://dx.doi.org/10.1080/02678379108257015

Tyler, K. (2006). Restructuring Policies and Workloads, Along with Providing Training and Support Services, Can Help Reduce Employee Stress. HR Magazines, 51. 
Uehata, T. (1991). Long Working Hours and Occupational Stress-Related Cardiovascular Attacks among Middle-Aged Workers in Japan. Journal of Human Ergology, 20, 147-153.

Ulrich, C., O’Donnell, P., Taylor, C., Farrar, A., Danis, M., \& Grady, C. (2007). Ethical Climate, Ethics Stress, and the Job Satisfaction of Nurses and Social Workers in the United States. Social Science \& Medicine, 65, 1708-1719.

http://dx.doi.org/10.1016/j.socscimed.2007.05.050

University of Cambridge (2014). Causes of Work-Related Stress. http://www.admin.cam.ac.uk/offices/hr/policy/stress/causes.html

World Health Organization (1948). Preamble to the Constitution of the World Health Organization as Adopted by the International Health Conference, New York, 19-22 June 1946; Signed on 22 July 1946 by the Representatives of 61 States (Official Records of the World Health Organization No. 2, pp. 100) and Entered into Force on 7 April 1948. The Definition Has Not Been Amended since 1948.

Zakaria, M., \& Azad, A. K. (2009). Journalism as a Profession in Bangladesh: An Overview. The Chittagong University Journal of Arts and Humanities, XXII, 236-248. 